\title{
Intrinsic values and the life framework of values: why we should go back to basics-comment to O'Connor and Kenter (2019)
}

\author{
Stijn Neuteleers ${ }^{1}(\mathbb{1}) \cdot$ Glenn Deliège ${ }^{2} \cdot$ Ullrich $_{\text {Melle }^{3}}$
}

Received: 4 February 2020 / Accepted: 22 May 2020 / Published online: 6 June 2020

(c) The Author(s) 2020

\begin{abstract}
The IPBES Framework aims to allow room for a plurality of values and recently proposed a move from 'Ecosystem Services' to 'Nature's Contributions to People'. O'Connor and Kenter (2019) argue that both approaches still disregard nature as an end in itself. Therefore, they propose a new conceptualisation of 'intrinsic value' and a new approach, labelled the 'Life Framework of Values'. This work is highly relevant, but we argue that there are some fundamental conceptual problems with their current account, in particular with the conceptualisation of intrinsic value, relational value, and their category of 'living as'. We argue that the changes made to the underlying framework of O'Neill add more confusion than clarification, that it is better to return to the original framework and to focus energy on making that framework applicable.
\end{abstract}

\section{Introduction}

A central element in the debate about nature and biodiversity is that these are valued by people in very different and possibly conflicting ways. To assess the value of nature or biodiversity, we need to find ways to deal with this plurality of values. This is what recent formulations of the IPBES framework try to do (Díaz et al. 2015, 2018; Pascual et al. 2017) and it will be the topic of IPBES's next important assessment report, namely 'Assessment on the diverse values and valuation of nature and its contributions to people', shortened as the Value Assessment, which is expected to be released in 2020.

Handled by Osamu Saito, Institute for GlobalEnvironmental Strategies, Japan.

Stijn Neuteleers

stijn.neuteleers@ou.nl

Glenn Deliège

glenn.deliege@ hogent.be

Ullrich Melle

ullrich.melle@kuleuven.be

1 Environmental Sciences, Open Universiteit (OU), Heerlen, The Netherlands

2 School of Arts (KASK), HoGent-University College Ghent, Ghent, Belgium

3 Husserl Archives, Institute of Philosophy, KULeuven, Leuven, Belgium
Recent versions of the IPBES framework promote a move from Ecosystem Services (ES) to Nature's Contributions to People (NCP). This conceptual move has already caused quite a stir in conservation circles (Maier and Feest 2016; Braat 2018; Masood 2018; Peterson et al. 2018) and has led to a rather antagonist debate between proponents of ES and of NCP. It is in this context that O'Connor \& Kenter (O'Connor and Kenter 2019) present a new framework in this journal, which they label as the 'Life Framework of Values'. This framework is supposed to be a more comprehensive and truer account of existing environmental evaluations and values than either the framework of ES or of NCP. Additionally, it aims to help resolve value conflicts in realworld cases.

\section{Promising}

The approach of O'Connor and Kenter has, in our view, several promising features. First, we believe that they have chosen a good conceptual foundation. The threefold distinction 'living from/with/in nature' of O'Neill and Light (2008) is a good starting point in environmental philosophy for valuing nature, because it distinguishes three conceptually different evaluative attitudes towards the environment and brings these in line with philosophical debates on valuation (Anderson 1993) and value incommensurability (Raz 1986; Wiggins 1987; Chang 1997; Hsieh 2008). Second, we agree that while NCP may overcome the narrow instrumental approach 
of ES by acknowledging relational values, it is still about a unidirectional flow from nature to people, as expressed in the label NCP itself. Third, we also agree that it is important to preserve a place for the inherent (or 'intrinsic') value of nature in any comprehensive framework of environmental values.

\section{Conceptual struggles}

While we believe that their approach is promising, we also think that there are conceptual difficulties with O'Conner and Kenter's approach. We will discuss three such difficulties here, namely concerning intrinsic value, relational value, and their category 'living as'.

First, as to intrinsic value, they start from a classical epistemic and political problem concerning intrinsic value claims, namely what the authors call the problem of moral trump card. Some environmental or ethical experts claim to have some general knowledge of objective intrinsic values of certain natural objects or processes. Armed with such knowledge, they consider themselves to be in the possession of a moral trump card that overrules all other concerns (e.g., land rights by indigenous people), since these other concerns are seen as subjective. The authors state that such an alloverruling moral trump card, based on knowledge of objective intrinsic values, does not fit well into a pluralist and democratic framework with different categories of values. Moreover, they add that a general claim that biodiversity has inherent value cannot give much practical guidance in concrete conservation issues. The authors, therefore, want to articulate an epistemically sounder, politically more tolerant and practically more applicable notion of intrinsic value.

To do so, O'Connor \& Kenter put forward their concept of 'articulated intrinsic value' (which they label somewhat counter-intuitively 'strong objective intrinsic value'). In their view, this concept avoids the shortcomings of both ecocentric objectivism (natural values exist independently of human valuers) and anthropocentric subjectivism (all values are human values). An 'articulated intrinsic value' is an objective intrinsic value that is subjectively expressed or articulated by us. For O'Connor \& Kenter, what is articulated as being objective, it is the fact that something is a good for something or someone, that something is satisfying a need of someone who has that need. Since we are discussing intrinsic values of nature, this something is a non-human being or entity. Therefore, what the authors have in mind seems close to the classical ecological value theory of Holmes Rolston III (2012): animals, plants, and even species can be regarded as valuing their own continued existence and all that supports their existence and propagation. What subjective values are for them are objective values for us.
This approach of O'Connor \& Kenter to inherent environmental value may be a defensible, but, unfortunately, they seem to ignore the difficult questions that need to be addressed by such an approach, questions that have preoccupied environmental philosophers for so long. Which being or entity in nature has perspectives, interests, and, consequently, a good: conscious animals, individual organisms, species, ecosystems, "a garden" as suggested by the authors, etc.? On what ground to decide? How can we know these interests? How to make sure that we do not project our own perspectives or interests on non-humans (the charge of anthropomorphism)? These questions resemble the questions utilitarian theories face: who's interest (what counts as utility), how to know, how to weigh, etc.

The authors want to leave an abstract and authoritarian value concept, for good epistemic and political reasons (cf. problems with intuitionism, elitism and 'moral trump cards'), but thereby they might have moved too much to the other side of the opposition between an obligation- or rightbased theory (deontology) and utilitarianism. Their idea of 'articulated inherent values' refers to non-human interests (what is 'good for' non-humans) articulated by humans. The whole inherent value talk could then drop out in favour of an extension of the 'circle of interests'. Either one takes a position where values play a central role and then a rightsbased ethics that protects rights-bearers against an utilitarian calculus is most plausible, or one moves towards a position where interests are central (traditionally variants of utilitarianism). The latter position brings in all the typical questions of utilitarianism (cf. above: who's interests, how to know, weighing, etc.). Moreover, the importance O'Connor $\&$ Kenter attaches to the human articulation of intrinsic values of nature (i.e., non-human interests), to make them somehow commensurable with other articulated values in an open deliberative framework, seems to offer little protection against real subjectivism, where only people's opinions matter. In the end, it is not clear why the 'intrinsic value' of nature is better preserved through their position and then by common subjectivist positions in social sciences (e.g., values are what people express in surveys).

Second, many approaches on environmental value nowadays put 'relational value' as the third category of environmental values, beside instrumental and intrinsic value of nature. This is, for instance, the case in recent proposals for the IPBES framework (Díaz et al. 2015, 2018; Pascual et al. 2017). However, there are some difficulties with O'Connor's and Kenter's conceptualisation of 'relational value'. First, on several places, they define relational values as the 'experiential analogues' of articulated values or as 'subjective intrinsic value' (O'Connor and Kenter 2019, pp. 1253, 1260). They give as example expressing awe or love for nature. However, making relational values the subjective or experiential 
analogue of intrinsic values brings relational and intrinsic values rather close to each other, making them hard to distinguish. Unsurprisingly, this is also what they then find as the outcome of their empirical research: 'the results displayed a strong co-emergence of articulated intrinsic and relational values. This reflects that participants may observe objective evaluative properties of non-human entities without reference to people, and, at the same time, relate to these entities more subjectively, giving expression to their own feelings and experiences' (O'Connor and Kenter 2019, p. 1260). This is hardly a surprise, since for them, those two ways of valuing are conceptually two sides of the same coin, namely value and the experience of value. Their struggle with relational values also reappears in a rather literal reading of O'Neill et al.'s second category of 'living in' nature: being amidst 'a flock of gannets diving', 'through a pod of dolphins', 'being in the sea', and 'paddle boarding with porpoises in the surf with us' (O'Connor and Kenter 2019, pp. 1258 , our italicization). These examples refer to a literal reading of 'in nature', while O'Neill et al. (2008, pp. 2-3) refer to something differently: 'We live in the world. (...) Environments matter for us for social, aesthetic, and cultural reasons (...) Particular places matter to both people and communities in virtue of embodying their history and cultural identities. (...) The social and cultural dimension has also a more local aspect, for example in the importance that local communities place on the "ordinary places" in or near which they live.' This seems close to conceptualisations of relational value in recent environmental philosophy (Hourdequin and Wong 2005; Muraca 2016; Neuteleers 2020) and as promoted in recent IPBES papers.

Third, the authors add a fourth category to the threefold distinction of O'Neill et al. (2008), namely 'living as the world/nature', 'which points to the more-thanhuman as self, individually, and collectively, for example as expressed in indigenous notions of oneness (...) and nondual spiritual experience' (O'Connor and Kenter 2019 , p. 1252). However, it is in our view not clear why this fourth category needs to be distinguished. While it refers to an important type of valuing nature, it seems plausible to interpret this as a type of relational valuing, namely one does not identify oneself with one's local place but also as being part of a larger nature (cf. Deep Ecology). One straightforward way to look at the 'from/ with/in' distinction is linking it with the distinction of instrumental/intrinsic/relational' values, which is increasingly becoming standard (cf. IPBES framework); these two categorisations of valuing attitudes towards nature largely converge. By adding a fourth category to the threefold distinction, one risks adding more confusion to the debate than necessary.

\section{Using the framework}

The authors aim to develop an applicable Life Framework. They present an interesting case about UK marine ecosystems, employing innovative methodologies such as transmitting value expressions through a compiled documentary film. A crucial question is what the goal is of evoking value expressions-e.g., mapping valuation, taking decisions, enhancing awareness, etc. One application of their Life Framework is categorising people's statements. However, it is unclear why such a categorisation according to a conceptual framework is relevant: why do we need to know which category of value a certain statement expresses? Moreover, in real-world statements, different types of valuing are mostly mixed, as the authors themselves recognize. Of course, it is potentially relevant in at least one way, as the authors themselves indicate indirectly, namely it shows that the methodology used allows evoking different types of valuing attitudes and thus that is not a reductionist one.

\section{Conclusion: the way forward for a life framework of values}

We strongly believe that the project which the authors are engaging in, namely constructing an applicable framework that is sensitive to the diversity of environmental values, is extremely relevant. Moreover, we share many of their intuitions and starting points. Unfortunately, we also believe that many of the changes made to the framework of O'Neill, Holland and Light framework add more confusion than clarification-we believe that it is better to go back to the basics of that framework.

Our constructive suggestion to the authors would be twofold. First, stay closer to the original conceptualisation of 'from/with/in' of O'Neill et al. The intuition behind intrinsic value is crucial in environmental valuation, but as a long tradition of debates in environmental philosophy revealed, it is often not productive to promote a very specific reading of intrinsic value (Weston 1985; O'Neill 1992; Light 2002). One better allows for a broader category, one closer to moral attitudes. In the authors' own words: 'The intrinsic value of nature in the broadest sense involves the importance of non- or more-then-human entities as an end in itself, rather than as a human end' (O'Connor and Kenter 2019, p. 1250). Also in the case of relational values, it seems advisable to stay closer to established interpretations of relational value, such as in the IPBES framework or in O'Neill's framework. Moreover, it is conceptually not necessary to add a fourth category ('living as'). It could be an option for practical reasons, but risks again to add more confusion to the debate. 
Second, with regard to application, categorising statements seems of little relevance. The crucial reason why distinguishing valuing attitudes is important is to keep the normative lens open and sensitive, namely in order not to forget certain valuing attitudes. A democracy wants to make choices that are sensitive to the whole range of values and to the diversity of evaluative attitudes. It also wants to make sure that its deliberation is inclusive of all social groups (possibly including more-than-human beings). The central challenge ahead is to make the existing 'from/with/in' distinction practical: how to use it for environmental assessments, in discussions about global biodiversity loss, for policy choices in particular conservation projects, etc. We strongly believe that policy-oriented and empirically-trained scholars such as O'Connor and Kenter can greatly contribute to this.

Open Access This article is licensed under a Creative Commons Attribution 4.0 International License, which permits use, sharing, adaptation, distribution and reproduction in any medium or format, as long as you give appropriate credit to the original author(s) and the source, provide a link to the Creative Commons licence, and indicate if changes were made. The images or other third party material in this article are included in the article's Creative Commons licence, unless indicated otherwise in a credit line to the material. If material is not included in the article's Creative Commons licence and your intended use is not permitted by statutory regulation or exceeds the permitted use, you will need to obtain permission directly from the copyright holder. To view a copy of this licence, visit http://creativecommons.org/licenses/by/4.0/.

\section{References}

Anderson E (1993) Value in ethics and economics. Harvard University Press, Cambridge

Braat LC (2018) Five reasons why the Science publication "Assessing nature's contributions to people"(Díaz et al. 2018) would not have been accepted in Ecosystem Services. Ecosyst Serv 30: A1-A2

Chang R (1997) Incommensurability, incomparability, and practical reason. Harvard University Press, Cambridge

Díaz S, Demissew S, Carabias J et al (2015) The IPBES conceptual framework-connecting nature and people. Curr Opin Environ Sustain 14:1-16
Díaz S, Pascual U, Stenseke M et al (2018) Assessing nature's contributions to people. Science 359:270-272

Hourdequin M, Wong DB (2005) A relational approach to environmental ethics. J Chinese Philos 32:19-33

Hsieh N (2008) Incommensurable Values. In: Zalta EN (ed) The stanford encyclopedia of philosophy (Fall 2008 Edition)

Light A (2002) Contemporary environmental ethics from metaethics to public philosophy. Metaphilosophy 33:426-449

Maier DS, Feest A (2016) The IPBES conceptual framework: an unhelpful start. J Agric Environ Ethics 29:327-347

Masood E (2018) The battle for the soul of biodiversity. Nature 560:423-425

Muraca B (2016) Relational values: a whiteheadian alternative for environmental philosophy and global environmental justice. Balk J Philos 8:19-38

Neuteleers S (2020) A fresh look on 'relational' and 'eudaimonic' values of nature: applicable distinctions derived from the debate on meaningfulness in life. Environ Values. Advanced Online Publication. http://www.whpress.co.uk/EV/papers/1748-Neuteleers.pdf

O'Connor S, Kenter JO (2019) Making intrinsic values work; integrating intrinsic values of the more-than-human world through the life framework of values. Sustain Sci 14:1247-1265

O'Neill J (1992) The varieties of intrinsic value. Monist 75:119-137

O'Neill J, Holland A, Light A (2008) Environmental values. Routledge, London

Pascual U, Balvanera P, Díaz S et al (2017) Valuing nature's contributions to people: the IPBES approach. Curr Opin Environ Sustain 26:7-16

Peterson G, Harmáčková Z, Meacham M et al (2018) Welcoming different perspectives in IPBES:"Nature's contributions to people" and "Ecosystem services". Ecol Soc 23:39

Raz J (1986) The Morality of Freedom. Clarendon Press, Oxford

Rolston H III (2012) A new environmental ethics: the next millennium for life on earth. Routledge, Abingdon

Weston A (1985) Beyond intrinsic value: pragmatism in environmental ethics. Environ Ethics 7:321-339

Wiggins D (1987) Needs, values truth. Essays in the philosophy of value. Blackwell, Oxford

Publisher's Note Springer Nature remains neutral with regard to jurisdictional claims in published maps and institutional affiliations. 